\title{
PERANCANGAN JARINGAN DENGAN ROUTER PC DAN VLSM (VARIABLE LESS SUBNET MASKING) : STUDI KASUS DI UNIVERSITAS BSI BANDUNG
}

\author{
Ade Mubarok \\ Universitas BSI Bandung \\ Jalan Sekolah Internasional No. 1-6, Bandung, Indonesia 40282 \\ ade.amb@bsi.ac.id
}

\begin{abstract}
Designing networks with PC Router is a network system which is made for the development of alternative systems that have been imposed on the Campus BSI Bandung University (UBSI) in the completeness of the information technology field. Network with a router PC system is expected to improve the performance of faculty, students and academic staff UBSI. The design and use of this network allows users, because it uses a system based GUI (Graphical User Interface) such as the Win box, Windows 7, Windows Server 2012. The method used for the development of the router configuration with VLSM (Variable Less Subnet Masking).
\end{abstract}

Keywords: Network, Subnet, Router, VLSM

\begin{abstract}
Abstrak - Perancangan jaringan dengan Router PC merupakan suatu sistem jaringan yang di buat untuk alternatif pengembangan sistem yang sudah diberlakukan di Kampus Universitas BSI Bandung (UBSI) dalam bidang kelengkapan teknologi informasi. Sistem jaringan dengan router PC diharapkan dapat meningkatkan kinerja dosen, mahasiswa, dan karyawan civitas akademika UBSI. Perancangan dan penggunaan jaringan ini memudahkan pengguna, karena menggunakan sistem berbasis GUI (Graphical User Interface) seperti Win box, Windows 7, Windows Server 2012. Metode yang digunakan untuk pengembangan konfigurasi router yaitu dengan VLSM (Variable Less Subnet Masking ).
\end{abstract}

Kata kunci : Jaringan, Subnet, Router, VLSM

\section{PENDAHULUAN}

Universitas BSI Bandung adalah salah satu perguruan tinggi swasta di Bandung. Berdiri sejak tahun 2009 sampai dengan sekarang. Dilihat dari perkembangan jumlah mahasiswa dari tahun ke tahun, pendaftaran Penerimaan Mahasiswa Baru (PMB) semakin bertambah dari tahun ke tahunnya, data tahun 2009-2013, jumlah mahasiswa kurang lebih 2000 mahasiswa dalam kurun waktu 4 tahun. Untuk kebutuhan ruang kelas tentunya bertambah, seiring dengan penambahan jumlah mahasiswa. Penambahan kelas untuk ruang teori dan ruang laboraturium diperlukan untuk penambahan jumlah mahasiswa UBSI yang semakin bertambah. Standar yang diterapkan kampus UBSI menggunakan jaringan internet setiap ruang kelas. Saat ini diterapkan jaringan internet oleh divisi Technical Support (TS) pada kampus UBSI. Infrastruktur jaringan yang sedang berjalan ternyata masih banyak kekurangan, diantaranya proses pengkabelan tidak tersusun dengan baik, topologi yang dipakai berbeda jenisnya, router board yang digunakan tidak ada cadangan, sehingga jika terjadi gangguan, akses internet error dan beban jaringan terlalu besar.

Selanjutnya beralih ke router RB1200 yang di gunakan di kampus UBSI. Jenis router yang digunakan adalah router board. Router board memiliki beragam seri dan interface 
yang disesuaikan dengan kebutuhan. Router board menggunakan router OS sebagai software/sistem operasinya. Beberapa contoh router board diantaranya adalah RB400 dan RB600 merupakan wireless board dan router jenis RB750, RB450G dan RB1000 merupakan embeded router.

Router PC adalah sebuah software yang dijadikan sistem operasi. Router PC ini di instal pada sistem operasi lain, misalnya Mikrotik OS di instal pada sistem operasi berbasis windows. Manfaat dengan menggunakan jenis router PC yaitu mudah dioperasikan dan memerlukan biaya yang tidak terlalu mahal.

Penggunaan sistem jaringan router PC pada kampus Universitas BSI Bandung, diharapkan menjadi alternatif solusi sistem jaringan untuk memenuhi kebutuhan komunikasi data dan akses internet.

\section{KAJIAN LITERATUR}

\section{Konsep Dasar Jaringan}

Berdasarkan teknologi transmisi, jarak dan area kerjanya jaringan komputer dibedakan dalam tiga kelompok:

\section{Wide Area Network (WAN)}

Merupakan jaringan komputer yang memiliki jarak sangat jauh, karena radiusnya mencakup sebuah negara atau bahkan benua. WAN terhubung melalui saluran telekomunikasi dan berinteraksi dengan jaringan lain menggunakan media yang disebut router.

2. Metropolitan Area Network (MAN)

MAN merupakan aleternatif pembuatan jaringan komputer antar kantor dalam suatu kota. Jangkauan MAN antara 10 sampai dengan 50 kilo meter.

3. Local Area Network (LAN)

LAN digunakan untuk menghubungkan komputer-komputer pribadi dan workstation dalam suatu perusahaan yang menggunakan peralatan secara bersamasama dan saling bertukar informasi.

Cara untuk menguraikan bagaimana komputer terhubung dalam suatu jaringan komputer dikenal dengan istilah topologi. Berdasarkan sifat cara menguraikan topologi, terbagi menjadi dua, yaitu topologi fisik dan topologi logika. Topologi fisik menguraikan layout aktual dari perangkat keras jaringan, sedangkan topologi logika meguraikan prilaku komputer dalam jaringan dari sudut pandang operator. Pada umumnya jaringan menggunakan satu atau lebih topologi fisik. Berikut adalah pemaparan dari topologi fisik, meliputi:

\section{Topologi BUS}

Topologi jaringan komputer BUS kedua ujung jaringan harus diakhiri dengan terminator. Laras konektor dapat digunakan untuk menyambung/menambah panjang. Merupakan topologi jaringan paling tua dalam teknologi jaringan Ethernet dan terdiri dari kabel coaxial yang menghubungkan komputer yang ada dalam jaringan dimana tiap kompter terhubung dengan sambungan konektor BNC jenis $\mathrm{T}$

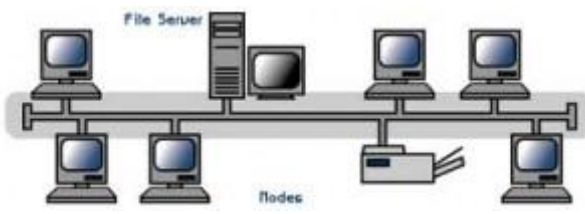

Gambar 1

Topologi BUS

Sumber :

http://www.jaringankomputer.org/topologijaringan-komputer/

\section{Topologi STAR}

Semua perangkat berputar disekitar hub pusat, sebagai kontrol komunikasi jaringan dan dapat berkomunikasi dengan hub lain. Rentang batas adalah 100 meter dari hub. Pada jaringan komputer yang paling umum digunakan dalam LAN adalah topologi tipe star. Topologi star dapat dibuat dirumah, kantor, sekolah dll. Semua komputer dalam topologi star terhubung ke perangkat sentral seperti hub, switch atau router. Komputer di jaringa yang biasanya dihubungkan hub, switch atau router dengan 1.527 Twisted Paiar (UTP) tau shelded Twisted Pair kabel. Topologi star ini sama halnya anda menarik satu kabel dari setiap komputer menuju pada pusat konsentrasi seperti Switch. Switch menangani Switching traffic keluar ke node lainnya dalam satu jaringan.

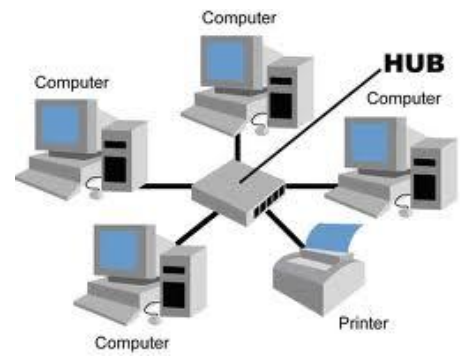

Gambar 2

Topologi STAR

Sumber :

http://www.jaringankomputer.org/topologijaringan-komputer/ 
3. Topologi RING.

Perangkat terhubung dari satu ke yang lain, seperti dalam sebuah cincin. Data token digunakan untuk meberikan izin untuk setiap komputer untuk berkomunikasi. Node berkomunikasi dengan formasi Ring, dengan setiap node berkomunikasi langsung hanya dengan upstream dan downstream tetangganya saja. Komputer atau perangkat memiliki dua tentangga yang berdekatan untuk komunikasi. Di ring network, semua pesan komunikasi perjalanan dalam direktori yang sama apakah searah jarum jam atau lawan arah jarum jam.

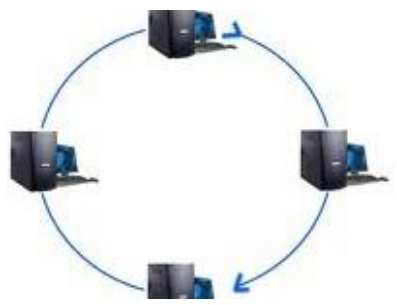

Gambar 2

Topologi RING

Sumber :

http://www.jaringankomputer.org/topologijaringan-komputer/

\section{Media Transmisi Terarah (Guided Transmission Data)}

Media transmisi terarah adalah Suatu media yang digunakan untuk mengirimkan data, dimana arah ujung yang satu dengan ujung yang lainnya sudah jelas. Contoh media transmisi terarah adalah kabel. Berikut adalah jenis-jenis media transmisi kabel (sumber :
MADCOM, sistem jaringan untuk pemula, Andi Offset, Yogya, 2010 ).

1. Coaxial

Coaxial adalah kabel data yang menggunakan material tembaga dimana terdapat dua bagian yaitu :

a. Kabel inti ditengah

b. Kabel serabut disisi samping dengan dipisahkan oleh suatu isolator.

\section{Twisted Pair}

Kabel berpilin (Twisted Pair), menggunakan kabel berpasangan dimana tujuannya untuk menghilangkan efek crosstalk. Banyak digunakan untuk jaringan LAN, dikarenakan mampu mengirimkan bandwidth dengan jumlah yang besar. Kabel ini menggunakan konektor seri Registered Jack (RJ), dan tergantung dari jenis kategorinya. Untuk kategori 2 menggunakan RJ11 sedangkan untuk kategori 5 keatas menggunakan RJ45. Apabila kedua ujung menggunakan aturan yang sama, kabel tersebut disebut StraightThrough, sedangkan bila berbeda disebut Cross-Over.

\section{Fiber Optic}

Jenis kabel fiber optic tidak menggunakan tembaga (cooper), melainkan menggunakan bahan serat optik, Sinyal yang dialirkan berupa berkas cahaya yang mampu mengirimkan bandwidth lebih banyak. Transmisi jenis fiber optic banyak digunakan untuk komunikasi antar Backbone, atau LAN dengan kecepatan tinggi.

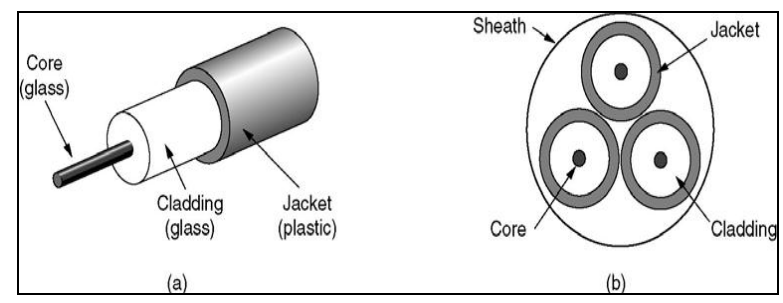

Gambar 3

(a) Fiber Optic Tampak Samping (b) Fiber Optic dengan 3 core Sumber : http://yulian.firdaus.or.id/2006/11/21/fiber-optic/

Berdasarkan jumlah sumber cahaya yang masuk pada core FO, kabel Fiber Optic dibagi menjadi 2, yaitu: Multimode dan Singlemode. Multimode memiliki jumlah sumber cahaya lebih dari 1, menggunakan diameter core dengan ukuran 50-100 micron. Singlemode memiliki jumlah sumber cahaya 1 , menggunakan diameter core ukuran 2-8 micron.

\section{Komunikasi Data}

Suatu konsorsium yang bernama International Standard Organization (ISO) membuat suatu rekomendasi model lapisan jaringan yang disebut dengan Open System Interconnections (OSI). Pada referensi model OSI ini, proses pengolahan data dibagi menjadi tujuh lapisan atau yang disebut dengan layer dan masing-masing lapisan (layer) tersebut 
memiliki fungsi masing-masing. Referensi model $O S I$ ini sering disebut juga dengan istilah arsitektur lapisan. Referensi model $O S I$ ini tidak membahas secara mendetail cara kerja dari lapisan-lapisan $O S I$, tetapi hanya memberikan gambaran suatu konsep di dalam menentukan proses apa saja yang harus terjadi pada suatu lapisan tertentu dan protokolprotokol apa yang dapat dipakai lapisan tersebut.

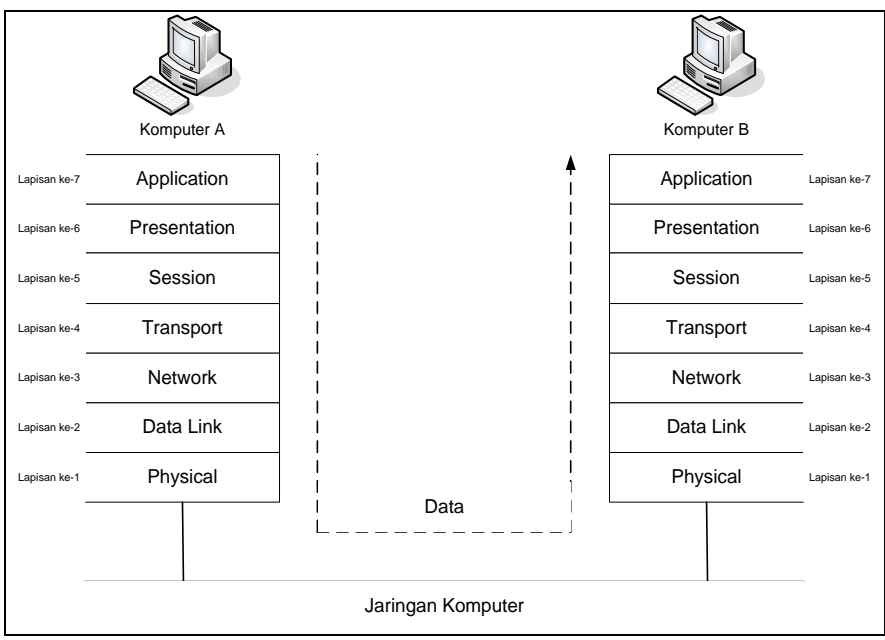

Gambar 4

Referensi Model OSI pada suatu jaringan komputer

Sumber : http://www.ardianta.tk/2010/perbedaan-osi-layer-dan-tcpip-layer.html/

Proses pengolahan data dari suatu lapisan ke lapisan lainnya pada referensi model OSI ini disebut data encapsulation, yaitu proses penambahan informasi depan (Header
Informations) data pada masing-masing lapisan yang disebut dengan Protocol Data Unit $(P D U)$.

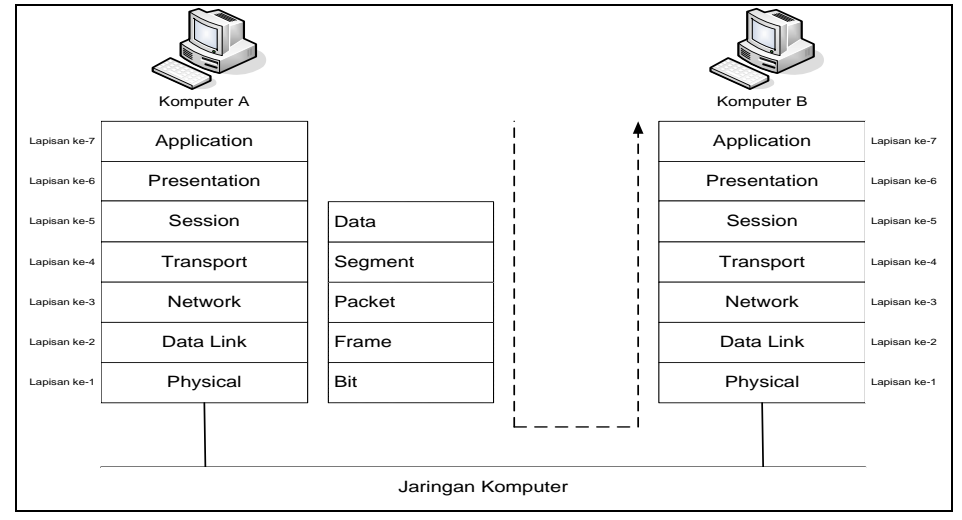

\section{Gambar 5}

Proses Encapsulation

Sumber : http://www.ardianta.tk/2010/perbedaan-osi-layer-dan-tcpip-layer.html/

Pada lapisan application, presentation dan session, informasi diubah menjadi data. Data tersebut kemudian diubah menjadi segment (data stream) pada lapisan transport. Setelah data diubah menjadi segment (data stream) pada lapisan transport ini, segment (data stream) tersebut diubah lagi menjadi packet (datagram) pada lapisan network. (sumber : MADCOM, sistem jaringan untuk pemula, Andi Offset, Yogya, 2010 ).

\section{Lapisan Presentation}

Agar suatu data atau informasi dapat terlihat oleh pemakai komputer (user), data atau informasi harus dapat ditampilkan baik dalam bentuk text maupun grafis pada monitor komputer pemakai. Lapisan presentation inilah bertanggung jawab atas penampilan text dan grafis pada monitor. Lapisan ini 
memberikan layanan (service) untuk konversi, sintaks, format dan enkripsi data. File format seperti ASCII, EBCDIC, JPEG, MPEG, TIFF, PICT, RTF, MIDI dan Quick Time bekerja pada lapisan ini.

2. Lapisan Session

Lapisan Sessions ini membuka, mengatur dan menutup session antara aplikasi. Protokol yang berfungsi pada lapisan ini antara lain adalah : NFS, NETBEUI, RPC SQL, X Windows System, Apple Talk Session Protocol (ASP) dan Digital Network Architecture Session Control Program (DNASCP). Lapisan Session ini juga menentukan apakai informasi yang diminta oleh pemakai berasal dari komputer lokal (Local Host) atau dari komputer lain (Remote Host) yang ada pada jaringan. Apabila informasi berasal dari komputer lain (Remote Host) yang ada pada jaringan, maka lapisan Session akan memulai untuk melakukan koneksi ke jaringan komputer.

3. Lapisan Transport

Lapisan transport ini bertanggung jawab atas keutuhan transmisi data yang dilakukan pada jaringan komputer. Lapisan ini sangatlah penting keberadaannya, karena lapisan ini yang memisahkan lapisan tingkat atas dengan lapisan bawah. Pada lapisan ini juga data dirubah menjadi Segment (Data Stream).

4. Lapisan Network

Lapisan network menyediakan topologi logika jaringan yang memungkinkan penggunaan alamat logika seperti IP Address. Dengan menggunakan alamatalamat logika ini, lapisan network ini berfungsi meneruskan paket-paket dari suatu node ke node lain pada jaringan komputer dan memilih jalur yang terbaik dalam meneruskan paket-paket dengan menambah informasi mengenai alamat logika yang dituju dan alamat asal dari paket. Peralatan jaringan seperti router bekerja pada lapisan ini.

5. Lapisan Data Link

Lapisan ini mengatur topologi jaringan komputer, error notifications dan flow control. Peralatan switch dan bridge bekerja pada lapisan ini. Lapisan ini menyediakan fasilitas alamat perangkat keras (hardware) dan mengolah paket dari lapisan di atasnya menjadi frame dengan menambahkan informasi mengenai alamat perangkat keras (MAC Address) yang dituju dan alamat asal. Lapisan data link ini dapat dibagi menjadi dua lapisan bawah
6. Media Access Control (MAC)

Lapisan sub Media Access Control (MAC) berfungsi untuk membuat frame dari bit 1 dan 0 yang diterima oleh lapisan physical serta memberikan hardware Address ke suatu Network Interface Card. AC Address atau disebut juga hardware Address dan terdiri dari dua bagian, yaitu : tiga byte untuk kode pabrik (vendor) yang diberikan oleh IEEE dan tiga byte untuk nomor serial unik untuk host yang diatur oleh pabrik (vendor). Penulisan MAC Address biasanya menggunakan enam angka heksa desimal untuk kode pabrik (vendor) dan enam angka heksa desimal untuk nomor serial. Contoh $M A C$ Address adalah : 00-0C-6E-60-7C-2E, 00-0C-6E adalah kode pabrik (vendor) dan $60-7 \mathrm{C}-2 \mathrm{E}$ adalah nomor serial untuk host. Semua peralatan aktif di jaringan komputer, baik Network Interface Card (NIC) maupun interface peralatan router dan switch menggunakan MAC Address untuk memberikan identitas dirinya di dalam jaringan komputer. Access Point (DSAP) untuk membantu lapisan bawah berkomunikasi dengan lapisan network.

7. Lapisan Physical

Lapisan physical ini menentukan spesifikasi koneksi fisik jaringan komputer, antara lain : tipe kabel, tipe konektor, hubungan pin konektor dengan kabel, tipe interface suatu peralatan jaringan komputer.

8. Lapisan Process / Application

Lapisan process / application referensi model $D o D$ dapat disamakan dengan gabungan lapisan apllications, presentation dan session pada referensi model OSI atau sering disebut juga dengan lapisan atas model $O S I$.

9. Protokol-protokol yang berfungsi pada lapisan process / applications referensi model $D o D$ antara lain adalah : Telnet, FTP, SMTP, TFTP, Kerberos, DNS, SNMP, RCP dan $X$ Windows.

10. Telnet

Telnet (Telecommunication Network) bermanfaat apabila seorang pemakai (user) ingin mengakses komputer lain dari jauh (remote host). Telnet menggunakan port 23 untuk berhubungan dengan lapisan transport.

11. File Transfer Protocol (FTP)

File Transfer Protocol (FTP) berfungsi untuk memindahkan file dari komputer satu ke komputer lain melalui jaringan komputer. FTP menggunakan port 21 dan bekerja dengan menggunakan protokol 
TCP yang menggunakan hubungan connection oriented.

12. Simple Mail Transfer Protocol (SMTP) Simple Mail Transfer Protocol (SMTP) berfungsi untuk pengaturan pengiriman $e$ mail. SMTP menggunakan port 25 dan menggunakan protokol TCP.

13. Trivial File Transfer Protocol (TFTP)

Trivial File Transfer Protocol (TFTP) adalah FTP yang disederhanakan dan menggunakan port 69. TFTP bekerja menggunakan protokol UDP yang menggunakan hubungan connectionless oriented yang tidak mengontrol hasil perpindahan file.

14. Kerberos

Kerberos adalah protokol untuk keamanan (security) yang menggunakan suatu peralatan yang disebut authentications server untuk memeriksa password dan enkripsi yang diperguankan.

\section{Adminitrasi Jaringan}

Jaringan yang menggunakan TCP/IP, tiap end-station melakukan komunikasi dengan server ataupun dengan end-station yang lain. Komunikasi bisa terjadi karena setiap station menggunakan protokol TCP/IP yang memiliki 32 bit alamat logikal yang bersifat unique. Tiap IP datagram terdiri dari Source IP address dan Destination IP Address yang keduanya menunjukkan identitas sumber dan tujuan.

Dalam jaringan yang sama dua device jaringan tidak diperkenankan menggunakan satu alamat yang sama, tetapi satu device jaringan dapat memiliki lebih dari satu IP address. Tipa bit pada masing-masing oktet jika bernilai satu, maka untuk urutan $\mathrm{N}$ bit dapat berisikan $2^{\mathrm{N}}$ IP Address (Address Space). Nilai minimum untuk masing-masing oktet 0 , atau semua bernilai 0 . Nilai maksimum untuk masing-masing oktet 1 , atau semua bernilai 1 , sehingga angka desimalnya adalah 255. Ipv4 menngunakan 32 bit address, maka total IP address adalah $2^{32}$, atau 4.294.296 IP Address. IP address merupakan pengalamatan dengan panjang 32 bit yang terbagi dalam dua bagian yaitu:

1. Identitas jaringan (network number)

2. Identitas host (host number)

Format pengalamatan yang digunakan dikenal dengan istilah dotted-decimal notation, yang masing-masing bagian terdiri 8 bit.

Contoh :

Biner : $10101100 \quad 00010000 \quad 10100000$ 00100011

Dotted Decimal $\quad$ : 172.16.160.35
Untuk memudahkan proses administrasi, Bit pertama dari alamat IP memberikan spesifikasi terhadap sisa alamat dari IP. Selain itu juga dapat memisahkan suatu alamat IP dari jaringan. Alamat Network (network address) biasa disebut juga sebagai netID, sedangkan untuk alamat host (host address) biasa disebut juga sebagai hostID. Ada 5 kelas pembagian IP address yaitu :

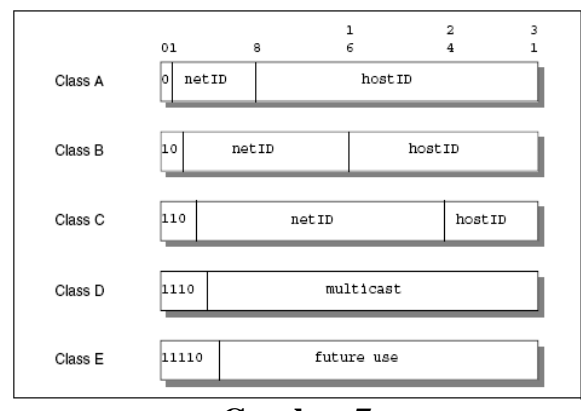

Gambar 7

Pembagian Kelas pada IP Sumber :

http://www.yudha.us/2011/02/pembagian-ipaddress-kelas-abc.html/

Kelas A : Menggunakan 7 bit alamat network dan 24 bit untuk alamat host. Dengan ini memungkinkan adanya 27-2 (126) jaringan dengan 224-2 (16777214) host, atau lebih dari 2 juta alamat.

Kelas B : Menggunakan 14 bit alamat network dan 16 bit untuk alamat host. Dengan ini memungkinkan adanya 214-2 (16382) jaringan dengan 216-2 (65534) host, atau sekitar 1 juta alamat.

Kelas C : Menggunakan 21 bit alamat network dan 8 bit untuk alamat host. Dengan ini memungkinkan adanya 221-2 (2097150) jaringan dengan 28-2 (254) host, atau sekitar setengah juta alamat.

Kelas D : Alamat ini digunakan untuk multicast. Kelas E : Digunakan untuk selanjutnya.

Kelas A digunakan untuk jaringan yang memiliki jumlah host yang sangat banyak. Sedangkan kelas C digunakan untuk jaringan kecil dengan jumlah host tidak sampai 254, sedangkan untuk jaringan dengan jumlah host lebih dari 254 harus menggunakan kelas B.

\section{METODE PENELITIAN}

\section{Teknik Pengumpulan Data}

Penulis melakukan beberapa metode yang menunjang dalam pembuatan tulisan ini, diantaranya : 
1. Observasi

Dalam metode ini penulis mengadakan kunjungan langsung ke bagian Technical Support Universitas BSI Bandung, dimana segala yang berhubungan dengan teknologi dan sistem informasi berpusat disini.

2. Wawancara

Penulis melakukan wawancara langsung dengan kepala bagian Technical Support (TS) Universitas BSI Bandung

3. Studi Pustaka

Dalam metode ini, pengumpulan data dilakukan dengan bersumber pada kajian referensi internet, buku pegangan judul"Sistem Jaringan Komputer Untuk Pemula" yang terkait dengan pengumpulan data sebagai bahan perlengkapan analisa penulis.

\section{Teknik Pengembangan Sistem}

Metode yang digunakan untuk pengembangan sistem yaitu dengan menggunakan metode Variable Less Subnet Masking (VLSM). Metode VLSM adalah melakukan pembatasan terhadap jumlah host dari sebuah subnet. Cara ini biasanya digunakan untuk melakukan konfigurasi router, karena router hanya memerlukan 2 ip address, sehingga tidak terjadi pemborosan ip address dan mencegah aksi sniffing dari hacker. Dimana cara kerjanya metode VLSM yaitu:

1. Menentukan subnet mask

Contoh : IP 192.168.20.0/27

Tabel 1

Menentukan Subnet Mask

\begin{tabular}{|c|c|}
\hline Subnet mask in biner & Subnet mask in decimal \\
\hline 11111111.11111111 .11111111 .11100000 & 255.255 .255 .224 \\
\hline
\end{tabular}

2. Menentukan subnet dan host dari subnet mask tersebut Untuk menentukan subnet dan hostnya dari subnet mask tersebut, ambil 8 bit terakhir atau ambil oket ke-4.

Oktet ke-4 yaitu 11100000 , dari octet ke4 tersebut jika di pisahkan menjadi :

$$
\begin{array}{llll}
111 & =\text { Subnet } \\
00000 & =\text { Host }
\end{array}
$$

3. Menentukan jumlah Subnet dan Host

$$
\begin{array}{lll}
\begin{array}{l}
\text { Jumlah Subnet } \\
=8 \text { Subnet }
\end{array} & : 2^{\mathrm{N}} \text { jadi } & 2^{3} \\
\begin{array}{l}
\text { Jumlah Host } \\
-2=30 \text { Host }
\end{array} & : 2 \mathrm{~h}-2 \text { jadi } & 2^{5}
\end{array}
$$

Dari ip 192.168.20.0/27 di dapatkan jumlah host sebanyak 30 host, karena kita hanya memerlukan 2 host maka kita harus masuk ke langkah berikutnya.

4. Menentukan subnet

Seperti yang kita ketahui bahwa ip 192.168.20.0/27 mempunyai 8 subnet dan subnetnya apa saja? Berikut cara mencarinya:

$$
111=\text { Subnet }
$$

\begin{tabular}{|c|c|}
\hline $\begin{array}{c}\text { Biner Octet ke } \\
-4\end{array}$ & Decimal in Full Subnet \\
\hline 00000000000 & $192.168 .20 .0 / 27$ subnet 1 \\
\hline $\begin{array}{llllllllllllll}0 & 0 & 1 & 0 & 0 & 0 & 0 & 0\end{array}$ & $192.168 .20 .32 / 27$ subnet 2 \\
\hline 01010000000 & $192.168 .20 .64 / 27$ subnet 3 \\
\hline $\begin{array}{llllllllllll}0 & 1 & 1 & 0 & 0 & 0 & 0 & 0\end{array}$ & 192.168.20.96/27 subnet 4 \\
\hline 1000000000 & $192.168 .20 .128 / 27$ subnet 5 \\
\hline 1001000000 & $192.168 .20 .160 / 27$ subnet 6 \\
\hline 11100000000 & $192.168 .20 .192 / 27$ subnet 7 \\
\hline 11110000000 & $192.168 .20 .220 / 27$ subnet 8 \\
\hline
\end{tabular}

$00000=$ Host dari bilangan biner di atas didapat 111 adalah subnet, maka untuk mendapatkan subnetnya, anda cukup mengurutkan bilangan biner tersebut dari awal.
Tabel 2

Mengurut Bilangan Biner

Setelah kita mengetahui subnetsubnet dari ip 192.168.20.0/27, maka kita dapat dengan mudah menentukan vlsm.

\section{Mencari VLSM}

Dari cara di atas telah di dapat subnetsubnetnya, maka untuk mencari vlsm kita tinggal memilih dari subnet tersebut untuk dijadikan vlsm. Misalkan kita mengambil subnet 192.168.20.160/27, maka langkah mencarinya adalah :

a. Menentukan bilangan biner dari octet ke-4 dan memilahnya menjadi subnet, vlsm, dan host.

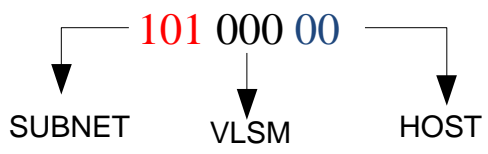


Setelah kita memilahnya, maka ip nya menjadi 192.168.20.160/30, mengapa menjadi /30? Karena kita menggunakan 2 bit host, sedangkan jumlah keseluruhan bit yaitu 32 bit.

b. Mencari VLSM

Untuk mencari vlsm, caranya hampir sama dengan cara mencari subnet. Anda tinggal mengurutkan bit vlsm dari 000 - 111.

\section{Tabel 3}

\section{Mencari VLSM}

\begin{tabular}{cl}
\hline $\begin{array}{c}\text { Biner } \\
\text { Oktet ke }- \\
4\end{array}$ & Decimal In Full Subnet \\
\hline 10100000 & $192.162 .20 .160 / 30$ subnet 1 \\
\hline 10100100 & $192.168 .20 .164 / 30$ subnet 2 \\
\hline 10101000 & $192.168 .20 .168 / 30$ subnet 3 \\
\hline 10101100 & $192.168 .20 .172 / 30$ subnet 4 \\
\hline 10110000 & $192.168 .20 .176 / 30$ subnet 5 \\
\hline 10110100 & $192.168 .20 .180 / 30$ subnet 6 \\
\hline 10111000 & $192.168 .20 .184 / 30$ subnet 7 \\
\hline 10111100 & $192.168 .20 .188 / 30$ subnet 8 \\
\hline
\end{tabular}

\section{PEMBAHASAN}

Jaringan yang bagus tidaklah identik dengan kecepatan akses saja. Banyak faktor yang mempengaruhi kualitas suatu jaringan. Gambar 8 menggambarkan skema jaringan komputer yang ada di Universitas BSI Bandung dan beberapa perangkat lainnnya yang digunakan adalah sebagai berikut

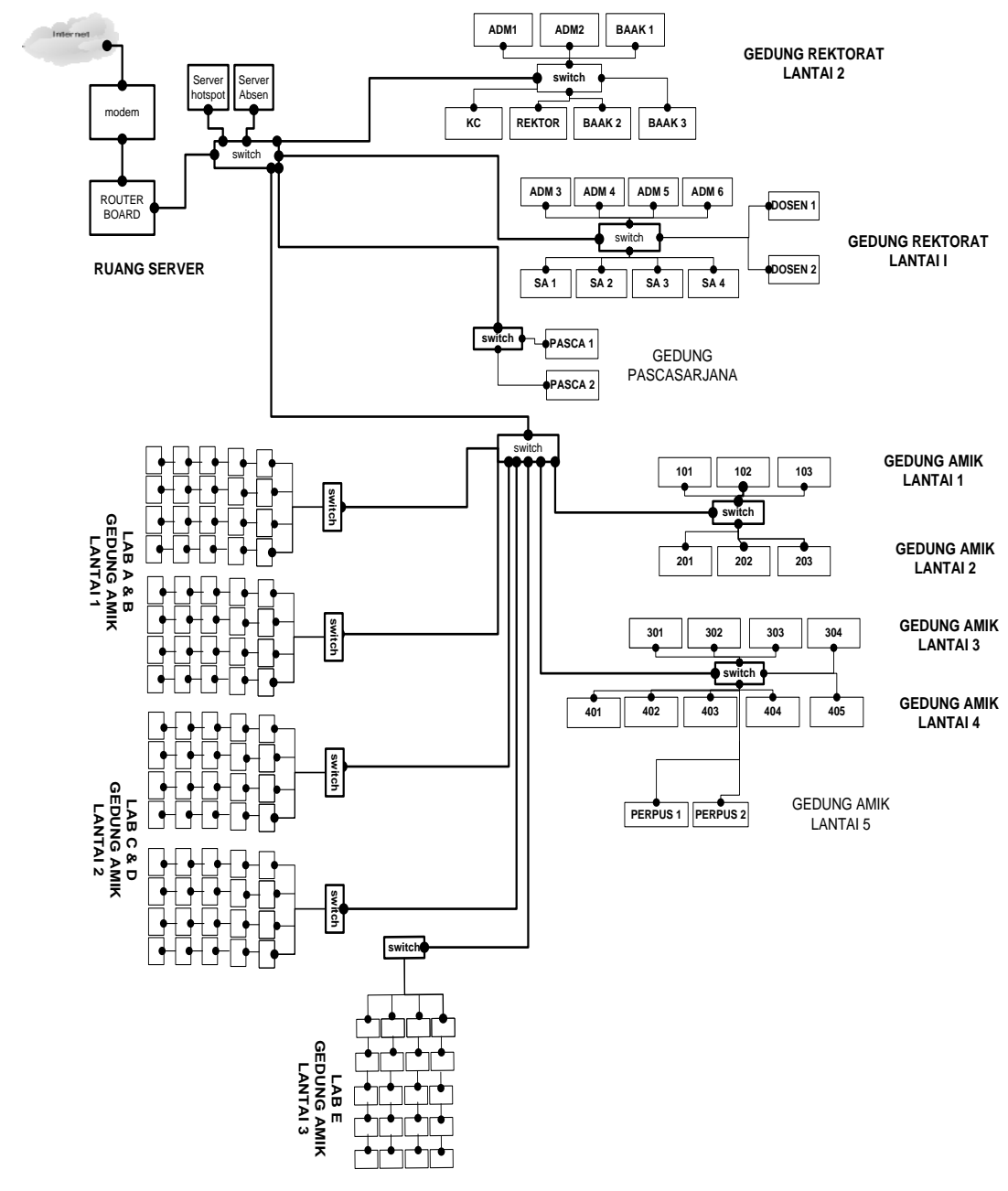

Gambar 8

Skema Jaringan Kampus UBSI 
Jumlah gedung di Universitas BSI Bandung yang terkoneksi dengan internet adalah gedung pasca yang terdiri dari 2 user, gedung rektorat terdiri dari 10 user untuk lantai 1 dan 2, gedung amik lantai 1 terdiri dari 3 ruangan kelas yaitu 101,102,103. Lantai 2 terdiri dari 3 ruangan yaitu 201, 202, 203. Lantai 3 terdiri dari 4 ruangan yaitu 301, 302,
303, 304. Lantai 4 terdiri dari 5 ruangan yaitu 401, 402, 403, 404, 405. Lantai 5 ruangan perpustakaan terdapat 2 user. Lab terdiri dari 5 lab dan masing-masing lab terdapat 1 server yang terkoneksi ke internet. Masing-masing ruangan mengunakan IP 172.16.160.x.

Untuk komputer server hotspot dan absensi spesifikasinya adalah:

Tabel 4

Spesifikasi Komputer Server

\begin{tabular}{ccccc}
\hline No & Server & \multicolumn{1}{c}{ Spesifikasi } & IP Address \\
\hline \multirow{3}{*}{ 1. Hotspot } & & - & Intel Pentium IV 3.0Ghz, 2,99 Ghz & \\
& & - & Memory 1 GB DDR II & $192.168 .22 . x$ \\
& & & \\
\hline \multirow{2}{*}{ 2. } & \multirow{2}{*}{ Absensi } & - & Intel Pentium IV 3.0Ghz, 2,99 Ghz & \\
& & - & Memory 512 GB DDR II & $172.16 .160 . x$ \\
& & & \\
\hline
\end{tabular}

Untuk komputer ruangan kelas, administrasi, dan staff akademik spesifikasinya adalah seperti tabel 6 berikut:

Tabel 5

Spesifikasi Komputer User

\begin{tabular}{|c|c|c|c|}
\hline No & Client & Spesifikasi/Client & IP Address \\
\hline 1 & Ruang Kelas & - Intel Pentium IV $2,4 \mathrm{GHz}$ & \\
\hline 2 & Administrasi & - Mainboard ECS P4VMM2 & \\
\hline 3 & Staf Akademik & - Memory 512 MB V-Gen & \\
\hline 4 & Dosen & $\begin{array}{ll}\text { - } & \text { Harddisk Maxtor } 80 \text { GB } \\
\text { - } & \text { NIC Via Rhine } \\
\text { - } & \text { Vga S3 Prosavage } 32 \mathrm{MB} \\
\text { - } & \text { Monitor LG 505 }\end{array}$ & 172.16.160.x \\
\hline
\end{tabular}

\section{PENUTUP}

\section{Kesimpulan}

Berkembangnya Teknologi Informasi ( IT ) dan semakin meningkatnya kebutuhan komunikasi global, sehingga diperlukan pengetahuan tentang Teknologi Informasi itu. Komunikasi data, dalam hal ini komunikasi data online tentunya sangat dibutuhkan oleh perusahaan-perusahaan dalam menjalankan dan mengembangkan usahanya. Perusahaan atau organisasi sangat membutuhkan suatu sarana yang dapat membantu dalam berkomunikasi antara satu dengan lainnya, maka dari itu dibutuhkan teknologi komunikasi data agar satu sama lain dapat saling berhubungan guna menjalankan dan mengembangkan usahanya. Teknologi Informasi terutama yang berhubungan dengan informasi global banyak dibutuhkan oleh masyarakat sekarang ini . Untuk membuat suatu Local Area Network diperlukan suatu router yang digunakan untuk menghubungkan beberapa PC dalam suatu jaringan yang luas.Untuk lebih meringankan biaya pengadaan router yang harganya relatif mahal maka sebuah router dapat dibangun dari sebuah Personal Computer ( PC ) dengan menggunakan operating sistem tertentu sehingga biaya yang digunakan untuk membanguan suatu jaringan luas bisa lebih ringan dan lebih bisa ditekan sehingga pembangunan sebuah jaringan luas tidak dikejar biaya yang mahal. Alat yang akan dibangun dalam hal ini PC Router mempunyai banyak keunggulan dibanding bila membeli alat yang langsung jadi dari pabrik. Disamping harganya lebih mahal bila terjadi kerusakan akan lebih sulit dalam memperbaikinya. Tetapi dengan menggunakan PC Router maka lebih murah dan perbaikannya juga lebih mudah. Dan kita dapat membuatnya sendiri untuk mempraktekkan teori-teori yang diberikan pada saat pelajaran di sekolah. Dengan penggunaan PC sebagai router maka kita dapat memanfaatkan PC yang ada yang tidak memerlukan spesifikasi yang tinggi untuk 
dapat digunakan sebagai router. Router yang dibangun dengan PC lebih mudah dalam maintenance dibandingkan dedicated router karena struktur fisik dedicated router cukup rumit. Dengan penggunaan PC sebagai router maka maintenance akan menjadi lebih mudah sehingga pada nantinya akan dapat dibangun jaringan luas yang baik sehingga komunikasi dan pengiriman paket data antar jaringan dapat berlangsung dengan baik.

\section{REFERENSI}

Ahmad Yani, Panduan Membangun Jaringan Komputer, Kawan Pustaka 2008

Edi S. Mulyanta, S.Si, Pengenalan Protokol Wireless Komputer, Penerbit Andi 2005

Edison Siregar, Langsung Mengelola Jaringan Lebih Efektif dan Efisien, Penerbit Andi 2010

Melwin Syafrijal, Pengantar Jaringan Komputer, Penerbit Andi, 2005

Rahmat Rafiudin, Panduan Membangun Jaringan Komputer Untuk Pemula, Penerbit Elek Media Komputindo, 2003

www.komputerjaringan.org (unduh : 16-012014)

http://ilmukomputer.org/2007/12/26/metodeip-address-lanjutan-vlsm/ ( unduh : 28-012014) 